\title{
EVOLUÇÃO DOS PROCESSOS DE TRIAGEM PSICOLÓGICA EM UMA CLÍNICA-ESCOLA
}

\author{
IMPROVEMENT OF THE TRIAGE \\ PROCESSES IN A PSYCHOLOGY CLINICAL SCHOOL
}

Hélvia Cristine Castro Silva PERFEITO
Sandra Augusta de MELO²

\begin{abstract}
RESUMO
Este trabalho é um relato de experiência sobre a evolução dos processos de triagem em um serviço de Psicologia aplicada de uma universidade federal. Apresenta breve histórico desse serviço de extensão na universidade e na rede de atendimento à saúde pública; procura compreender o desenvolvimento de suas rotinas no âmbito acadêmico, técnico e assistencial; observa que a evolução desses procedimentos está relacionada com a busca de ocupação de um lugar que venha articular ensino, pesquisa e extensão e conclui, finalmente, que o serviço em questão não pôde realizar esta tarefa por causa de questões institucionais, ou seja, das dificuldades de integração e articulação entre os diferentes segmentos envolvidos, gerando a necessidade de se repensar e construir uma nova prática.
\end{abstract}

Palavras-chave: triagem psicológica; clínica-escola de psicologia; psicologia clínica.

\begin{abstract}
This paper is an experience report about the evolution of the triage processes in a applied psychology service of a federal university: shows a brief history of this extension service that attends the public health net; it looks for to comprehend the development of its routines in the academic, technical and assistance field; observes that the evolution of these proceedings connects
\end{abstract}

\footnotetext{
(1) Psicóloga do Núcleo de Psicologia Aplicada da Universidade Federal de Uberlândia; Especialista em Psicologia Clínica. Endereço para correspondência: Rua 1 no 91 - Jardim Panorama Araguari/MG Cep: 38440-240.

(2) Psicóloga e Doutora do Núcleo de Psicologia Aplicada da Universidade Federal de Uberlândia e docente do Centro Universitário do Triângulo. Endereço para correspondência: Av.: João XXIII nº 698 Santa Maria - Uberlândia/MG Cep: 38408-056. E-mail: saugusta@nanet.com.br
} 
to the search of a role to articulate the teaching, research and extension and finally concludes that, this service, can not manage this task because the institutional issues, it means, the difficulties of integration and articulation between the different parts involved, creating the need to change and build a new practice.

Key words: psychologist triage; psychology clinical school; clinical psychology.

\section{INTRODUÇÃO}

A Psicologia Clínica é um campo de aplicação da Psicologia que impõe desafios aos educadores. Somente estudar Psicologia Clínica não ensina a ser clínico: ser clínico se aprende sendo, ou seja, a ênfase do estudo teórico nesta área não refuta a idéia de que a clínica se aprende no contato com o paciente. Esta é a importância crucial das clínicas-escola que, por lei, devem fazer parte dos serviços de Psicologia aplicada ligados aos cursos.

Entretanto, não há modelos pré-formados para a constituição destes espaços de aprendizado que, para além de sua função no ensino, devem sustentar-se num tripé que inclui ainda a extensão e a pesquisa - cerne da função que as universidades desempenham na sociedade, ao menos idealmente.

A rotina das clínicas-escola é complexa e envolve diversos segmentos e atividades diferentes para servir a objetivos também diferentes, embora interdependentes. Práticas de disciplina, estágios supervisionados, os interesses e necessidades da população e a necessidade de disponibilizar e estruturar dados que possam ser utilizados para pesquisas coexistem e precisam ser atendidos no espaço dos serviços de Psicologia aplicada. Estas três vertentes - ensino, pesquisa e extensão - não são de fácil articulação numa proposta única de trabalho, muito embora façam parte de um só projeto que, de uma forma mais ampla, podemos dizer tratar-se do projeto de "universidade" - espaço no qual se pretende produzir, transmitir e aplicar conhecimentos.

Apesar de ser uma necessidade óbvia, a articulação entre extensão, ensino e pesquisa, que consta nos objetivos de todas as universi- dades, não se mostra, ao menos na área da Psicologia, um denominador fácil de ser atingido. Este trabalho descreve a trajetória de uma busca nesse sentido e procura avaliar a eficácia dos procedimentos utilizados na sua realização; é um relato de experiências e esforços empreendidos para realizar os objetivos descritos acima, e uma avaliação do que se pôde conseguir com a atual organização da rotina dos atendimentos em triagem na clínica-escola da Faculdade de Psicologia da Universidade Federal de Uberlândia, constituída como Núcleo Integrado de Psicologia (NIPSI).

\section{O LUGAR DO ENSINO DA PSICOLOGIA APLICADA}

Uma articulação perfeita entre a pesquisa, a extensão e o ensino deveria fundar-se em pesquisas epidemiológicas que mapeassem a clientela e os atendimentos oferecidos pelos serviços de Psicologia aplicada das universidades. Somente por meio desses dados, poder-se-ia delinear as ações e possibilitar correções de rumo na extensão e no ensino, norteando até mesmo a construção dos currículos. Entretanto, na prática isso não é uma tarefa fácil.

Num serviço de Psicologia aplicada a rotina envolve vários aspectos que se entrelaçam, como: recepção; construção do kit de prontuário, com seus formulários, pela secretaria; pré-seleção de clientes, segundo a clientela-alvo ou o critério de existência de vagas; forma de registro dos dados; uso da clínica por profissionais e estagiários com diferentes propósitos; uniformidade da rotina de registro, até o relacionamento entre pessoas que incorporam a clínica de forma definitiva e aqueles 
que somente ocasionalmente lançam mão de seu espaço e procedimentos.

A estrutura e a dinâmica dos espaços de aplicação da psicologia nas universidades, parecem ser indicativos de como são integrados,ou não, o ensino, a pesquisa e a extensão numa dada instituição.

Uma reflexão e a melhoria deste espaço envolvem uma articulação de todos os segmentos: técnicos administrativos, alunos, professores, supervisores e clientela e isso não é algo simples de se conseguir. Trata-se, na verdade, de um desafio de gestão, numa organização - a universidade - que, histórica e culturalmente, carrega entraves administrativos peculiares.

Aparentemente, a necessidade de uma avaliação e mudança de funcionamento em um empreendimento tão complexo, como os centros de Psicologia aplicada, fica enormemente dificultada, pois as questões de gestão nas universidades, especialmente as públicas, são desvalorizadas ou caem por terra diante de outra prioridade: a política tanto interna como externa à instituição.

A operacionalização do funcionamento das clínicas-escola é tão desafiante que vários encontros entre profissionais têm sido promovidos e artigos têm sido produzidos sobre as iniciativas institucionais que buscam um funcionamento ótimo a partir de questões específicas. Exemplo disso são os trabalhos de Fontolan (1997) e Bartz (1997) que discutiram suas experiências nos atendimentos de plantão psicológico no $\mathrm{V}$ Encontro Estadual de Clínicas-Escola da Universidade São Judas, assim como o de Morato e outros (1997), que fizeram uma reflexão sobre as implicações teórico-práticas em plantão psicológico no XXVI Congresso Interamericano de Psicologia em São Paulo.

Não obstante essas e muitas outras iniciativas realizadas por outras faculdades que possuem um centro de Psicologia aplicada, não há um modelo recomendável e adequado aos propósitos desse órgão que possa ser chamado padrão, ainda mais pelas diferenças regionais e pelas diferenças nas estruturas das universidades.
Estas dessemelhanças inviabilizam a generalização, embora não os intercâmbios. As clínicas-escola de Psicologia têm que buscar caminhos singulares para a construção de rotinas adequadas e para a solução das questões que Ihes são impostas pelo desafio de cumprir sua vocação que é tão complexa.

Esses desafios não aparecem descolados dos desafios da própria profissão. O espaço se institui com a mesma complexidade e com os mesmos problemas que se relacionam à construção da identidade profissional agravados, entretanto, por questões de ordem prática que pedem soluções também práticas.

Num trabalho de 1983, Lopez estuda as clínicas-escola da cidade de São Paulo e conclui que as dificuldades destes órgãos refletiam as indefinições do psicólogo quanto ao seu lugar e suas práticas diante das solicitações da comunidade. Hoje em dia, estas dificuldades são encaradas como parte da diversidade do campo da Psicologia e da própria condição humana mutável, que exige do psicólogo uma postura criativa e flexível, possibilitando que haja um trânsito por diversos saberes e fazeres (Ancona-Lopez, 1996).

É essa mesma flexibilidade e essa criatividade que a construção de um espaço clínico-educacional impõe às universidades. Ou seja, não há soluções prontas, mas todas a serem criadas mediante novos e antigos desafios.

Apesar de dificilmente poder ser copiada, a estruturação dos serviços de atendimento à saúde pública em clínicas-escola pode fomentar reflexões, discussões e servir de parâmetro para outras iniciativas.

Se observado através de sua história, pode-se dizer que o Núcleo de Psicologia aplicada da Universidade Federal de Uberlândia inicialmente funcionava quase que exclusivamente como um órgão centrado no ensino. A ênfase exclusiva nessa vertente acabava gerando enormes filas de espera, em que as pessoas dificilmente eram atendidas, além do que não havia uma padronização em seus procedimentos. Nessa época ocorriam fatos curiosos, como a identificação de 
clientes em espera que já haviam falecido sem terem sido atendidos.

Num segundo momento, houve uma implementação do serviço de extensão e o direcionamento do foco para as necessidades da comunidade, o que gerou um atendimento muito maior em quantidade do que em qualidade. Nesta fase, a preocupação com a clientela ocupou o centro; entretanto, as tentativas de atendimento em quantidade eram predominantes, o que indisponibilizava a clínica para o exercício de uma busca da excelência.

Posteriormente, então, deu-se ênfase na qualidade. Os profissionais se voltaram para a possibilidade e necessidade de construir um espaço em que o foco recaísse sobre a excelência no atendimento, já que o órgão não tinha as características de um serviço ambulatorial strictu sensu, mas antes de um local em que diferentes interesses deveriam ser conciliados, como discutido anteriormente. Surgiu, no grupo de trabalho, a consciência de que o poder público deveria arcar com aquilo que the caberia e a compreensão de que o NIPSI seria mais uma peça na estrutura do atendimento à saúde mental, com a peculiaridade de estar ligada a um órgão que visa ao ensino e à pesquisa.

A necessidade de uniformizar procedimentos, gerar e disponibilizar dados para pesquisa veio junto com essa fase e essa consciência. Discute-se este ponto adiante.

\section{HISTÓRIA DO NIPSI}

\section{O NIPSI e a distritalização da atenção à saúde mental em Uberlândia}

O Serviço de Psicologia Aplicada da Universidade Federal de Uberlândia (UFU) foi organizado em 1979, em conformidade com a lei 4119, que versa sobre a criação dos cursos de Psicologia e dos serviços de Psicologia aplicada nas universidades brasileiras.

Desde sua fundação até 1988 , todos os atendimentos no NIPSI eram realizados por supervisores docentes e seus estagiários. A partir de então, duas psicólogas iniciaram o trabalho de atender à alta demanda em espera gerada nos anos anteriores pelos estágios supervisionados, já que, com a finalização do tempo previsto para os estágios e/ou o desligamento dos alunos por ocasião da sua formatura, os pacientes eram deixados em espera. Além disso, muitos prontuários eram abertos sem que os pacientes fossem efetivamente atendidos.

Em 1992, outra psicóloga foi incorporada à equipe e passou a realizar triagens de pacientes, além de atender os pacientes que ficavam ou voltavam às filas de espera após os estágios.

A partir desse ponto, inaugurou-se uma nova frente de atuação para a clínica-escola além do ensino: a atividade de extensão propriamente dita, com a presença de profissionais psicólogos contratados especificamente para isto.

Em 1996, o grupo de psicólogos, contando então com quatro membros, começou a se organizar em torno da idéia de humanizar o atendimento, extinguir as filas de espera e desenvolver um processo de triagem adequado aos seus propósitos.

Com a participação da coordenação do NIPSI, o processo de triagem passou, então, a vigorar na forma de estágio supervisionado de 10 estagiários do curso de Psicologia da UFU, selecionados a cada ano, com o objetivo principal de atender às demandas infantil, adolescente $\mathrm{e}$ adulta, originárias de todo o município e ainda de municípios vizinhos.

Em 1997, foi instituído o Plano Diretor de Saúde Mental de Uberlândia, por meio de fórum de discussões desde o ano anterior. Foram estabelecidas diretrizes e normas sobre a assistência, a promoção de saúde e a reinserção social do portador de sofrimento psíquico. Com isso, houve uma reformulação do sistema existente visando à racionalização do modelo de atenção à saúde, viabilizada pela efetiva interinstitucionalização das partes envolvidas.

O NIPSI foi incluído nesse processo como um dos dispositivos de atendimento à saúde 
mental dentro dos recursos do município e, com isso, várias alterações foram possíveis com a finalidade de buscar a excelência ao em vez da quantidade de atendimentos.

Algumas mudanças foram realizadas obedecendo princípios sanitários definidos pelo Sistema Único de Saúde (SUS). No novo arranjo, a cidade foi dividida em setores sanitários definidos em norte, sul, leste, oeste e centro, que passaram a ter dispositivos de saúde que delimitavam suas ações para as populações dos bairros do setor. Assim, cada centro de saúde não mais atenderia a toda a cidade, mas somente à população dos bairros próximos.

Nesse redimensionamento coube ao NIPSI atender pacientes procedentes do distrito sanitário leste do município.

Essas medidas organizaram o atendimento municipal à saúde mental como um todo, possibilitando a otimização dos recursos, gerando melhoria qualitativa no atendimento e reduzindo filas de espera. Isto pôde ser observado em todos os setores e para o NIPSI abriu novas possibilidades que o colocavam frente a frente com sua função enquanto uma clínica-escola, ou seja, constituir-se um núcleo de apoio ao tripé ensino-pesquisa-extensão.

\section{O PROCESSO DE TRIAGEM NO NIPSI}

O processo de triagem é a porta de entrada dos pacientes ao "universo Psi", pois os clientes desconhecem o que é um serviço psicológico, uma vez que este tipo de trabalho não tem repercussão em seu universo cultural e educacional.

Se o paciente não se sentir mobilizado pelo primeiro atendimento, talvez não prossiga na sua busca por ajuda e, nesse sentido, a triagem promove uma conscientização maior do paciente bem como da família em relação às suas dificuldades.

Entrevistas de triagem costumam ser mais do que coleta de dados com os quais se organiza um raciocínio clínico sumário que vai orientar o encaminhamento. As entrevistas tomam a forma de uma intervenção breve, já que ao dar aos clientes uma oportunidade de se engajarem em seu próprio atendimento, torna-os responsáveis por seus problemas (Ancona-Lopez, 1995).

O simples acolhimento já tem significado importante para muitos clientes. Por acolhimento entende-se uma disposição afetiva do psicólogo, uma atitude de escuta que visa receber, aceitar, em que a expressão do sofrimento já proporciona alívio ou mesmo certa clareza em relação à situação vivida, criando condições para modificá-la.

É dessa maneira que o processo de triagem é realizado e encarado no NIPSI: não como um mero processo de seleção de demanda ou coleta de dados da história do cliente, mas como parte da intervenção psicoterapêutica propriamente dita. Nessa fase há uma clarificação da situação psicodinâmica individual ou grupal, para além do simples levantamento de dados e isso tem efeito psicoterapêutico. Essa discussão está de acordo com as idéias de Ancona-Lopez (1995), quando discorre sobre o psicodiagnóstico também como processo de intervenção. As altas durante o processo de triagem são um indicativo relevante que corrobora com tal idéia.

A triagem, para o psicólogo, é um processo de conhecimento de quem procura por atendimento e que busca, muito além dos sintomas, saber qual é o sofrimento e onde estão suas causas. Para muito além dos sintomas, das queixas, das designações nosológicas, o processo de conhecimento do cliente procura uma compreensão mais ampla e mais aprofundada do sujeito e do grupo em que ele está inserido. Encontramos respaldo para isso em trabalhos como o de Brasil (1999), que discute sobre a compreensão do fenômeno psicológico incorporado aos determinantes econômico-sociais e culturais presentes nas demandas populacionais que buscam o serviço de saúde mental.

O processo de triagem pode ser contínuo à psicoterapia quando o triador é o mesmo que atenderá o cliente, ou pode constituir uma etapa à qual se seguirá outra nova, com outro profissional, quando houver encaminhamento. Outra 
possibilidade é que a alta ocorra durante o processo de triagem.

Falando de outra forma, a triagem é um processo psicodiagnóstico que tem início, meio e fim, dura de 4 a 5 sessões, mas cujo fim não será percebido pelo cliente quando for um processo contínuo, mas somente quando houver necessidade de que o paciente seja encaminhado.

Essa necessidade de encaminhamento pode vir do caso, quando há uma indicação para a qual o triador não está preparado para atender; do triador, quando este está sobrecarregado de atendimentos; ou também quando há solicitação de pacientes para atendimento para outros estágios supervisionados do curso de psicologia. Neste caso, os pacientes são triados e encaminhados aos supervisores conforme a necessidade e especificações do tipo de caso a que o estágio se destina a atender.

É preciso ressaltar, entretanto, que esse modelo não foi assim concebido desde o início do funcionamento do NIPSI, mas é o resultado da práxis desenvolvida ao longo dos anos pela equipe de psicólogos.

No NIPSI, a triagem é considerada uma etapa importante nas suas três frentes de atuação: extensão, ensino e pesquisa, uma vez que proporciona atendimento à comunidade, é o ponto forte do estágio oferecido pelos psicólogos e é uma rica fonte de dados que pode gerar pesquisas diversas.

Avaliando a história do modelo de atendimento feito pelos psicólogos técnico-administrativos adotado no NIPSI, pode-se dizer que no início ele se prestava a diminuir a fila de espera e a atender os casos que foram atendidos mas não concluídos pelos estágios. Em outras clínicas-escola de Psicologia pode-se também perceber a constante preocupação com filas de espera, como ilustrado no trabalho de Peres (1997), que retratou uma tentativa de minimizar estas filas, por meio da utilização de triagem grupal, objetivando dinamizar o atendimento, conhecer melhor a clientela e planejar intervenções mais efetivas.
A triagem dos pacientes ingressantes no NIPSI até o final do ano de 2002 foi realizada no sistema de plantões por 10 alunos estagiários, tendo como supervisores os psicólogos do NIPSI. Nos plantões os alunos permaneciam disponíveis para atender a demanda, durante todo o turno a eles designado, em dois períodos de quatro horas.

O estágio em triagem tinha por objetivo oferecer oportunidade ao aluno de vivenciar este processo de recepção e avaliação dos pacientes, delineando os diversos quadros psicopatológicos, e desenvolvendo o raciocínio clínico.

Os plantões funcionavam em dias fixos da semana para cada faixa etária: infantil, adolescente e adulto. Este procedimento visava facilitar à população saber quando procurar por atendimento. É preciso ressaltar que, sempre que havia excedente de pacientes, os plantões eram fechados. Esta decisão foi tomada pelos supervisores, tendo em vista o número de pacientes que podiam ser atendidos pelos supervisores psicólogos, pelos seus estagiários e pelos estágios que eram oferecidos e que solicitavam pacientes ao sistema de triagem.

Aqueles pacientes triados nos plantões eram atendidos imediatamente após a conclusão da triagem objetivando-se, desta forma, um melhor nível de resolutividade e alívio dos sofrimentos psíquicos, especialmente pelo aproveitamento da motivação do paciente no momento em que procurava por ajuda na clínica psicológica. Além disso, esta forma de proceder evitava a formação de filas de espera.

Sob o ponto de vista da pesquisa, pode-se dizer que os prontuários gerados no serviço de plantão, tal qual era realizado até o fim do ano de 2002, ou seja, de forma padronizada, se encontram em condições de oferecer material organizado para pesquisas clínicas diversas e estão à disposição de pesquisadores da Instituição.

Vale ressaltar que, casos que não passaram pela triagem ficaram fora de levantamentos estatísticos por não seguirem padrões de registro, sendo impossível qualquer tipo de controle sobre eles. 


\section{O REGISTRO DE DADOS}

Por estar inserido em uma faculdade, o NIPSI não escapa à sua vocação para fomentar e produzir pesquisa. A preocupação com o levantamento de dados estatísticos da triagem ocorre desde 1996, pois percebeu-se a riqueza de dados que eram gerados pelos atendimentos. Naquela ocasião, começaram-se a fazer tabulações dos casos triados em relação à faixa etária, ao sexo, ao encaminhamento, à procedência (bairros) e queixas. Pesquisas semelhantes são encontradas nos trabalhos de Térzis e Carvalho (1988) e Barbosa (1994) sobre a identificação da população atendida em clínicasescola.

As tabulações eram feitas manualmente sobre o material bruto dos prontuários dos pacientes. Estes prontuários muitas vezes encontravam-se incompletos, por falta de estruturação de registro de dados e de procedimentos de pesquisa. Exemplos deste trabalho são mostrados em anexo (anexo 1).

Pode-se observar naquele registro (anexo 1) o número elevado de pacientes atendidos em triagem naquela ocasião. Este fato devia-se à falta de normas e à delimitação da população atendida, abrangendo todo o município e ainda municípios vizinhos. A maioria dos atendimentos era realizada em grupo e os profissionais supriam a alta demanda com outros estágios além da triagem, chegando-se a ter 30 estagiários atuando no atendimento, sob supervisão de quatro psicólogos.

Daquela época até o presente, pode-se observar, como já dito anteriormente, uma mudança que adequou o tipo de atendimento ao perfil de uma clínica-escola: a troca da quantidade pela qualidade e a preocupação em extinguir filas de espera-que por si só constitui uma ranhura nos princípios éticos.

Nos anos de 1999 a 2001, foram instituídas novas formas de registro de dados nos prontuários dos pacientes atendidos em plantão. Para isso foram feitas visitas a clínicas-escola de outras universidades, foram colhidas informações sobre seus procedimentos de captação, seleção e atendimento da demanda, assim como sobre documentação em prontuários e demais rotinas da secretaria.

Foram criados: um novo modelo de anamnese, um para atendimento de adultos e outro para crianças e adolescentes, uma "Ficha com dados do atendimento"; uma folha de "Autorização para uso dos dados clínicos e epidemiológicos em pesquisas e publicações"; e, por último, um formulário para "Levantamento de dados epidemiológicos e clínicos dos processos de triagem" - que consiste num resumo dos dados do caso com vistas a pesquisas. Esta súmula, assim como outros formulários, deverão sofrer alterações segundo a avaliação que é feita sobre eles, a partir do seu uso.

\section{CONCLUSÕES}

A intenção implícita na formatação do processo de triagem em vigor durante os anos de 1996 até 2002, e dos procedimentos de registro de dados que evoluíram a partir de sua prática foi constituir a porta de entrada de pacientes no NIPSI e, dessa maneira, uniformizar rotinas e registros de forma a disponibilizar dados para a realização de investigações, servindo a todos os pesquisadores ligados ao curso de psicologia.

A proposta desse processo de triagem era a articulação do serviço de extensão dentro do ensino clínico com os diversos estágios, em diferentes abordagens, oferecidos pelo curso. Isto é, como porta de entrada, a triagem identificaria e direcionaria os pacientes segundo o diagnóstico e as solicitações dos supervisores. Os pacientes seriam encaminhados para os estágios segundo particularidades de cada um.

Mas isso não se efetivou na prática, já que não houve uma regularidade no oferecimento dos estágios supervisionados dos professores que eram abertos por períodos temporários e atendiam a demandas específicas e, em geral, não requisitavam os pacientes ao serviço de triagem já estruturado, preferindo captá-los de outras maneiras. 
As razões para isso podem ser atribuídas à falta de comunicação imposta pela distância entre as carreiras docente e administrativa e a falta de articulação, ou seja, trabalho em equipe; e também à decrescente abertura de estágios pelos professores-supervisores, uma vez que a oferta de estágios foi bastante reduzida por receber pontuação baixa na avaliação dos docentes.

Chegou-se à conclusão que o processo de triagem, embora idealizado para propósitos de integração, tornou-se algo fechado em si mesmo, visto que havia poucas possibilidades de encaminhamento de pacientes, ficando os atendimentos quase restritos aos profissionais responsáveis por essa tarefa e seus estagiários.

Atualmente, a demanda espontânea da triagem recebe atendimento pela própria equipe de psicólogos e seus estagiários em quase sua totalidade, fato comprovado em levantamento recente (Perfeito e Melo, 2003). Este fato aparece agravado pela alta demanda causada pelo fechamento dos atendimentos pela rede pública, que hoje se restringe à atenção aos casos graves, ficando o NIPSI como única referência para atendimento de casos leves e moderados do setor leste do município. Resulta disso uma superdemanda, a qual não é possível escoar no atual modelo de funcionamento: no ano de 2002, não foi possível manter o funcionamento semanal do plantão, esgotando-se as vagas nos primeiros meses do ano.

O sistema de plantão e triagem - como porta de entrada e instrumento de articulação entre os diversos segmentos (psicólogos, técnicos, supervisores, professores, alunos, estagiários, e clientela) e entre os diversos propósitos dentro da concepção de universidade (como órgão sustentado e sustentador do tripé ensino / pesquisa / extensão) - não conseguiu atingir seus propósitos, tal como concebidos pela equipe de psicólogos do serviço de Psicologia aplicada.

Mais uma vez são exigidas do psicólogo a flexibilidade e a criatividade para lidar com as dificuldades institucionalizadas e, ao mesmo tempo, com demandas e mudanças diversas.

Apesar de uma certa frustração pelo fracasso do modelo construído nestes últimos anos, é preciso pensar em novas alternativas que sejam ao mesmo tempo adequadas, flexíveis e viáveis à realidade da Instituição.

Um alerta, entretanto, essa experiência parece deixar e ele se refere à origem das dificuldades encontradas na otimização dos procedimentos de atendimento em saúde pública psicológica no formato das clínicas-escola: a questão científica que nos leva a investigar formas de melhor atender à população, as maneiras de humanizar a relação com a clientela, melhores técnicas adequadas ao atendimento institucional não são suficientes se não forem discutidas e resolvidas as questões concernentes à gestão desse órgão.

Concluindo de outra forma, não obstante os intercâmbios e as pesquisas, e a busca das clínicas-escola de Psicologia por caminhos singulares para a construção de rotinas adequadas à solução das questões que lhes são impostas pelo desafio de cumprir sua vocação que é tão complexa, é preciso perceber que soluções que visam aos problemas ligados à prática da Psicologia não são suficientes sem a organização de aspectos estruturais e funcionais do espaço destinado a essa prática. Estes dois aspectos não podem realizar-se em separado.

As clínicas-escola e, de forma mais alargada, os núcleos de Psicologia Aplicada carecem, antes de qualquer coisa, de ser compreendidos como um sistema e uma organização viva, com todas as necessidades de gestão que lhe são peculiares.

\section{RERERÊNCIAS BIBLIOGRÁFICAS}

ANCONA-LOPES, M. (1983, abr/jun). Considerações sobre o atendimento fornecido por clínicas-escola de psicologia. Arquivos Brasileiros de Psicologia; 2(35): 123-135. 
(org.) (1995). Psicodiagnóstico: Processo de Intervenção. São Paulo: Cortez.

ANCONA-LOPEZ, S. (1996, jan/jun). Reflexões sobre entrevistas de triagem ou: na prática a teoria é outra. Interações: Estudos e Pesquisas em Psicologia; 1(1):47-57.

BARBOSA, J. I. C. SILVARES, E. F. de M. (1994, set). Uma caracterização preliminar das clínicas-escola de Fortaleza. Estudos de Psicologia; 3(11):50-56.

BARTZ, S. (1997). Plantão psicológico: atendimento criativo à demanda de emergência. $V$ Encontro Estadual de Clínicas-Escola. Caderno de resumos, São Paulo, Universidade São Judas, p. 69.

BRASIL, A. M. R. C. (1999, jul./dez). Um percurso de raciocínio clínico através da práxis multidisciplinar no atendimento à comunidade. Interações: Estudos e Pesquisas em Psicologia; 8(4):105-127.

FONTOLAN, V. (1997). Uma experiência no atendimento de plantão psicológico. $\mathrm{V}$ Encontro Estadual de Clínicas-Escola. Caderno de resumos, São Paulo, Universidade São Judas, p. 67.

MORATO, H. T. P., AlBUQUERQUe, A. C.F., BARBANTE, L. F., CAMARGO, R. F.,
GALVÃO, L. F., HALPERN, M., HULLE, A. C., JARDIM, A. B., LAM, U., LERNER, R., MUNHOZ, C., NUNEZ, A. L., RAMALHO., S. A., SOARES, M. B., STREB, A. \& SUGANO, C. F. (1997). Plantão psicológico como modalidade de atendimento em instituição: implicações teórico-práticas. Resumos / Abstracts XXVI Congresso Interamericano de Psicologia, São Paulo, SP, p.179.

PEREZ, V. L. A. (1997, fev/ago). Triagem psicológica grupal: procedimento e resultados obtidos com lista de espera de crianças, adolescentes e adultos, em uma clínica-escola de psicologia. Paidéia: Cadernos de Psicologia e Educação; 12/13:63-76.

PERFEITO, H. C. C. S. e MELO, S. A. (2003). Caracterização da população infantil atendida entre 2000 e 2002 na clínica-escola de psicologia da Universidade Federal de Uberlândia. No prelo.

TERZIS, A., CARVALHO, R. M. L. L. (1988, out/dez). Identificação da população atendida na Clínica-Escola do Instituto de Psicologia da Puccamp. Arquivos Brasileiros de Psicologia; 4(40): 87-97.

Recebido para publicação em 4 de junho de 2003 e aceito em 16 de fevereiro de 2004. 
Anexo 1: Tabulações de dados sobre os atendimentos realizados no ano de 1996

Tabela 1. Distribuição da população atendida em triagem por faixa etária e sexo, em 1996.

\begin{tabular}{lccc}
\hline & Masculino & Feminino & Total \\
\hline Infantil & 174 & 118 & 292 \\
Adolescente & 61 & 96 & 157 \\
Adulto & 80 & 227 & 307 \\
3a idade & 05 & 33 & 38 \\
\hline Total & 320 & 474 & 794 \\
\hline
\end{tabular}

Fonte: Prontuários de pacientes atendidos em 1996.

Tabela 2. Distribuição de pacientes atendidos por idade, em 1996.

\begin{tabular}{|c|c|c|c|c|c|}
\hline Faixa etária & & Faixa etária & & Faixa etária & \\
\hline $0-5$ & 79 & $26-30$ & 66 & $51-55$ & 15 \\
\hline $6-10$ & 171 & 31-35 & 59 & $56-60$ & 11 \\
\hline $11-15$ & 101 & $36-40$ & 45 & 61-65 & 09 \\
\hline $21-25$ & 102 & $46-50$ & 21 & $71-75$ & 02 \\
\hline
\end{tabular}

Fonte: Prontuários de pacientes atendidos em 1996.

Tabela 3. Distribuição de pacientes por tipo de queixas, em 1996.

\begin{tabular}{|c|c|c|c|c|}
\hline & Infantil & Adolescente & Adulto & $3^{\mathrm{a}}$ idade \\
\hline Ansiedade & 0 & 0 & 19 & 0 \\
\hline Atraso desenv. Neuro-psico-motor & 15 & 0 & 0 & 0 \\
\hline Depressão & 0 & 11 & 52 & 16 \\
\hline Dificuldade escolar & 111 & 14 & 0 & 0 \\
\hline Dificuldade de relacionamento & 0 & 21 & 55 & 0 \\
\hline Insegurança e timidez & 0 & 10 & 0 & 0 \\
\hline Medo e fobia & 0 & 0 & 18 & 0 \\
\hline Nervosismo e agressividade & 37 & 21 & 44 & 0 \\
\hline Problema de comportamento infantil & 24 & 0 & 0 & 0 \\
\hline Problema sexual & 0 & 0 & 17 & 0 \\
\hline Problema somático & 0 & 0 & 23 & 0 \\
\hline Não consta & 37 & 26 & 45 & 0 \\
\hline Total & 224 & 103 & 273 & 16 \\
\hline
\end{tabular}

Fonte: Prontuários de pacientes atendidos em 1996. 